\title{
Green bonds, transition to a low-carbon economy, and intergenerational fairness: Evidence from an extended DICE model
}

Sergey Orlov (orlov@iiasa.ac.at)

Elena Rovenskaya (rovenska@iiasa.ac.at)

Julia Puaschunder (julia.puaschunder@gmail.com)

Willi Semmler (semmlerw@newschool.edu)

\section{Approved by \\ Pavel Kabat \\ Director General and Chief Executive Officer \\ IIASA}

February 2018 


\section{Contents}

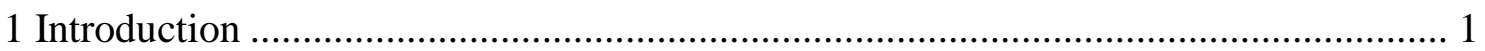

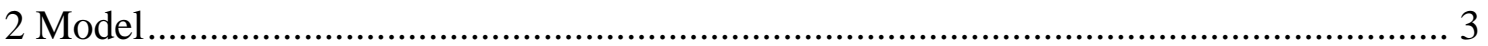

2.1 Original DICE-2013R model ............................................................................. 4

2.2 Augmented DICE model: Green bonds ............................................................. 6

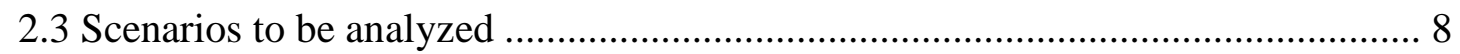

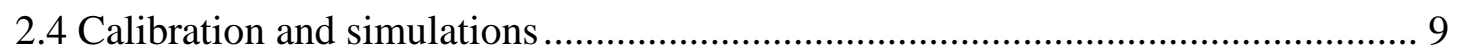

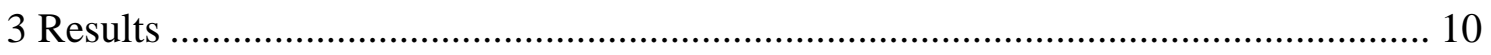

3.1 Intergenerational problem in DICE-2013R ....................................................... 10

3.2 Bonds shorten the period of welfare sacrifice ..................................................... 10

3.3 Pareto-optimal mitigation possible ........................................................................ 11

3.4 Mitigation success and climate change damages ............................................... 12

3.5 Sensitivity analysis w.r.t. the bond's interest rate ............................................. 13

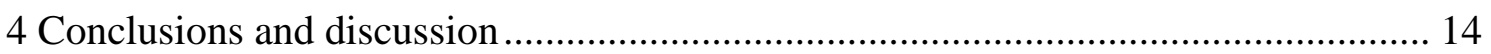

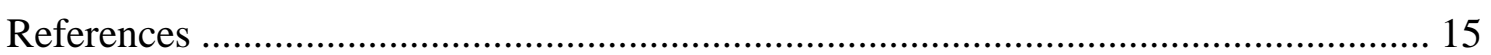

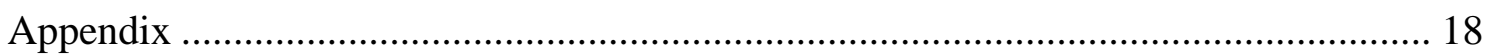

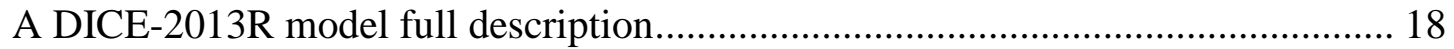

B Two alternative ways of representing the climate change damage to GDP in the

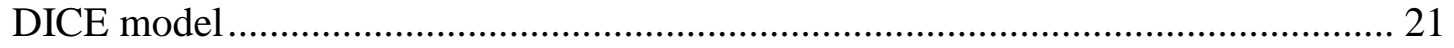

C Sensitivity analysis w.r.t. damage function ...................................................... 22 


\section{Abstract}

Perceived intergenerational unfairness is one of the obstacles for a rapid transition to a low carbon economy whereby current generations have to carry the burden of paying for mitigation, while the next generations will enjoy the benefits for free. Green bonds are believed to be able to distribute the burdens over generations more evenly. In this paper, we examine whether green bonds can indeed resolve the intergenerational inequity challenge. To do so, we employ the DICE model and supplement it with bonds and green tax through which future generations repay the debt. We show that bonds can reduce but cannot completely eliminate the intergenerational inequities. Lower interest rates shorten the initial time period when the society is worse off if a mitigation policy is implemented. Additional compensation mechanisms ensuring that the current generation retains the consumption level equal to the one without mitigation are needed to achieve a Pareto improvement of the mitigation scenario for all generations.

Graphical abstract:

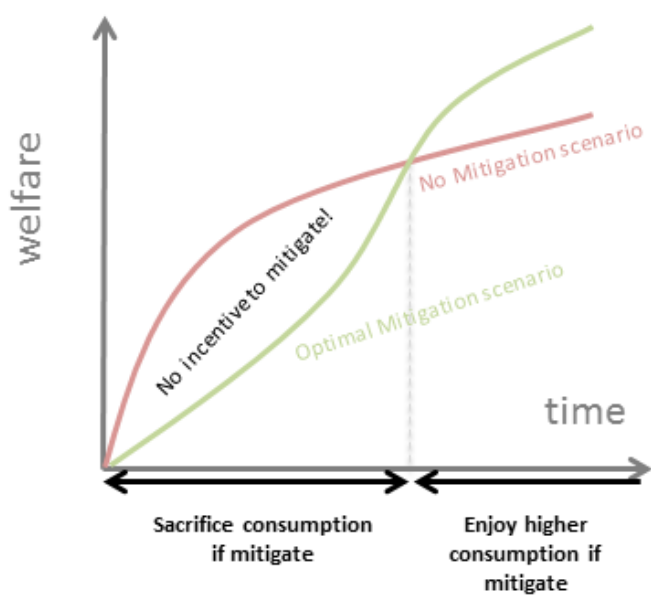

Pareto-improving to No Mitigation scenario, but not to Optimal Mitigation scenario

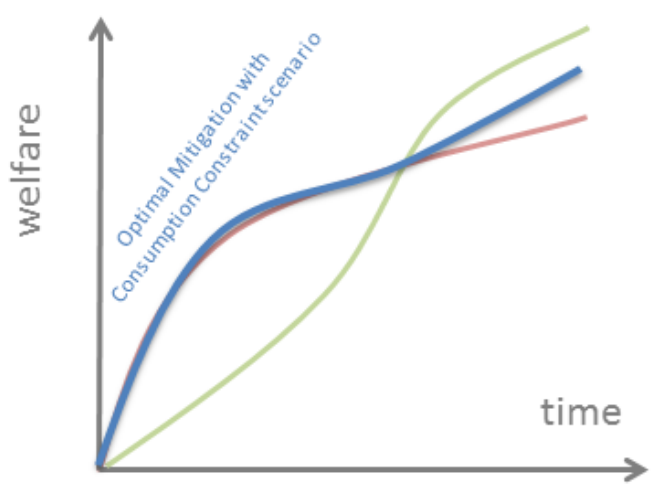

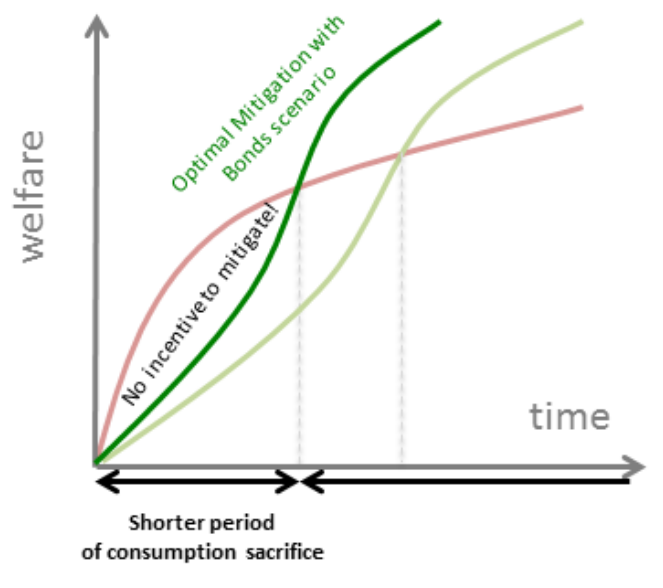

Pareto-improving to No Mitigation scenario \& Optimal Mitigation scenario, but not to Optimal Mitigation with Bonds scenario

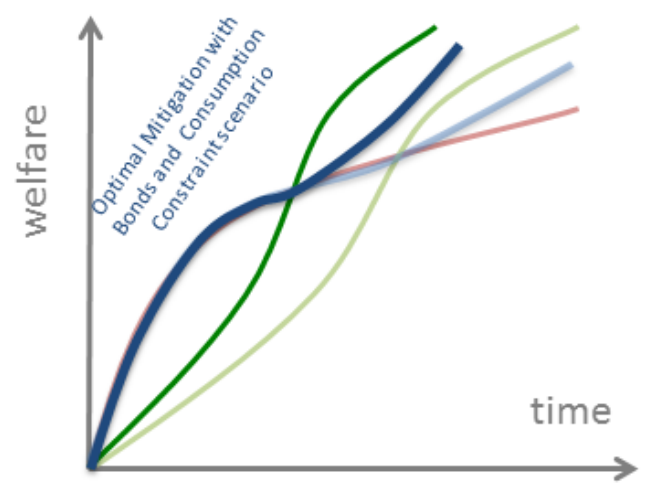




\section{Acknowledgments}

The main results of this paper have been presented at the 23rd International Conference "Computing in Economics and Finance" of the Society for Computational in Economics, held on June, 28-30 2017 in New York, USA, as well as at the First IIASA Summer Workshop on Green Growth Modeling held at June, 262017 in Laxenburg, Austria. We would like to thank the audiences at both events for comments. We also would like to thank two colleagues, Nebojsa Nakicenovic and Artem Baklanov for inspiring discussions that helped us crisping the ideas behind this paper. 


\section{About the Authors}

Sergey Orlov is a Research Assistant of the Advanced Systems Analysis (ASA) Program at IIASA. He is also a Lecturer at the Optimal Control Department of the Faculty of Computational Mathematics and Cybernetics, Lomonosov Moscow State University, Russia.

Elena Rovenskaya is the Program Director of the Advanced Systems Analysis (ASA) Program at IIASA. She is also a Research Scholar at the Optimal Control Department of the Faculty of Computational Mathematics and Cybernetics, Lomonosov Moscow State University, Russia.

Julia Puaschunder is a Research Associate of The New School for Social Research, New York, USA. She is also an YSSP 2016 participant of the Advanced Systems Analysis (ASA) Program at IIASA.

Willi Semmler is the Henry Arnhold Professor of Economics at The New School for Social Research, New York, USA. He is also a Research Scholar of the Advanced Systems Analysis (ASA) Program at IIASA. 


\title{
Green bonds, transition to a low-carbon economy, and intergenerational fairness: Evidence from an extended DICE model
}

\author{
Sergey Orlov \\ Elena Rovenskaya \\ Julia Puaschunder \\ Willi Semmler
}

\section{Introduction}

The Paris Climate Agreement signed in 2015 by 195 UNFCCC member countries recognizes the importance of combining mitigation, adaptation and finance to effectively deal with global warming and its negative consequences worldwide. While the climate change scientific community is convinced that urgent actions are needed to prevent further global warming and that keeping the global average temperature below $1.5^{\circ} \mathrm{C}$ above the pre-industrial level is necessary to avoid catastrophic damages (Schleussner et al. 2016), economists are concerned with finding feasible incentives and financing mechanisms of emission reduction and of dealing with future damages (High-Level Commission on Carbon Prices 2017; Stern 2008).

Carbon tax is one practical way to punish GHG emitting industries and to finance the transition to a low carbon economy (Baranzini, Goldemberg, and Speck 2000; Poterba 1991). However, curbing carbon emissions via the introduction of a carbon tax may negatively affect the welfare of the current generations by lowering economic activity, reducing net income of households, and possibly affecting employment (on the latter, see (Kato et al. 2015)). Current generations will have to carry the burden of paying for the transition to a low carbon economy, while the next generations will enjoy its benefits for free. Such intergenerational uneven treatment is one of the reasons why politicians are hesitant to go ahead and implement the carbon tax that is likely to be un-favored by the public - and as (Lucas and Stokey 1983) argue, the democratically elected governments might not want to make the current generation worse off in terms of taxation.

In order for a mitigation policy to be accepted and work effectively, it is recognized and emphasized that attention should be paid to fairness within the generation (Marron and Morris 2016) and, notably, across generations (Sachs 2015). So called green bonds (or climate bonds) have been suggested as an innovative approach to finance mitigation costs - and possibly future damages - thereby making climate policies more feasible, speeding up the transition to a low carbon economy, increasing welfare and ensuring greater intergenerational equity and fairness (Flaherty et al. 2016; Sachs 2015). Green bonds can be issued by companies, municipalities, states and sovereign governments, by international institutions to raise money and finance mitigation, as well as a variety of future-oriented long-term environmental and climate related projects and 
activities (Flaherty et al. 2016; “The World Economic Forum Report” 2015). As a debt instrument, by which investors lend money to an entity, bonds allow to borrow funds from the populace for a defined period of time at a variable or fixed interest rate. Historically, bonds have been used to fund large-scale projects ranging from infrastructure (Semmler et al. 2011) to wars (Kimble 2006, ch. 1). For example, the UK used loans to finance their participation in World War II, whereby the US was the creditor - the repayment of this loan was stretched out until recently (Kindleberger 1985). The first green bonds were issued by the European Investment Bank in 2006. In 2016 the bond market reached a level as high as 80 billion $\mathrm{USD}^{1}$ that are used to fund environmentfriendly projects.

To provide evidence of whether green bonds can be effective in reducing intergenerational unfairness and hence in enhancing the acceptance of more aggressive mitigation, (Sachs 2015) was the first to use a stylized modeling framework. He considered and analyzed an overlapping-generations (OLG) model, in which individuals' wages are negatively affected by the amount of greenhouse gases (GHGs) in the atmosphere, as well as by the mitigation efforts of the government. Policy makers, aiming to balance the interests across generations, can affect the wealth distribution by applying bonds and taxes policies. This model demonstrates that if the discounted social cost of a GHG emissions increment is higher than the cost to mitigate this increment, then it is possible to come up with such a policy solution combining bonds and taxes that the current generation is as well off (in welfare terms) as it would be without any mitigation; at the same time, the welfare of future generations increases or at least remains at the same level, while the global warming is abated. (Andersen, Bhattacharya, and Liu 2016) extended Sachs's OLG model by making both production and emissions endogenous, dependent on production factors, and obtained qualitatively the same result as Sachs. Thereby they confirmed that one can find such a policy combining bonds and taxes that a low-carbon economy can be achieved without reducing any generation's welfare.

Another step forward was done by (Flaherty et al. 2016), who suggested an economic growth model with endogenous GHG emissions and mitigation costs covered by bonds. In this model bond issuance and bond repayment take place in separate subsequent stages of fixed length. Numerical calculations presented by Flaherty et al. show that green bonds can indeed help mitigate GHG emissions down to pre-industrial level and debt can be repaid in a finite time.

It might be that the optimistic conclusions of (Andersen, Bhattacharya, and Liu 2016; Flaherty et al. 2016; Sachs 2015) are due to the simplified nature of the considered models and particular assumptions chosen. Notably, all models are lacking any explicit representation of the carbon cycle, which may prevent the economy from a realistic emulation of the impact of emission reduction on economic damages of global warming. OLG models by (Sachs 2015) and (Andersen, Bhattacharya, and Liu 2016) are lacking the analysis from the social planner's perspective: They do not examine how close or far their solutions are to the socially optimal ones, rather they just show a possibility of a Pareto improvement of some exogenously defined solutions, which poses a concern to their feasibility. Similar concerns extend also to (Flaherty et al. 2016) who prescribe the

\footnotetext{
${ }^{1}$ For more information, see https://www.climatebonds.net/files/files/2016\%20GB\%20Market\%20Roundup.pdf [Accessed 22.11.2017]
} 
periods of bond issuance and bond repayment without analyzing how much the social welfare function is affected by these assumptions and hence how acceptable these measures will be for the society which aims to improve social welfare. These, among other considerations, lead to the question whether the conclusions on the effectiveness of green bonds for removing intergenerational burden sharing derived by the above literature remains accurate under more realistic assumptions on the relations between production, emissions, temperature and mitigation policies and concerning high social welfare.

A modeling framework that is well-suited to examine those questions is the DICE model family, see (W. Nordhaus 2008; W. D. Nordhaus 2017a, [b] 2017; W. Nordhaus and Sztorc 2013). The DICE model that exists in several versions is a stylized integrated assessment model representing the global economy and global climate using a few dynamic equations. Despite their simplicity, the DICE equations capture, in a tractable way, the entire causal loop between economic growth, related industrial emissions and concentrations, global temperature increase, its negative economic effects - so called climate change losses - as well as the effect of mitigation policies. The DICE model has been calibrated to real data, which enables its application to inform a policymaking process on GHG emission reduction (Metcalf and Stock 2015). Particularly, it was used for estimation of the social cost of carbon for the US government (Government Accountability Office 2014).

In this paper, we intend to examine whether green bonds can be used to finance mitigation in an economy, in which abatement decisions are made endogenously with the aim to maximize the social welfare function over a finite (long enough) time horizon. We employ the DICE model and extend it by adding green bonds, ${ }^{2}$ which can be used to compensate the economic losses from mitigation. Once a certain level of emission reduction is achieved, the economic activity is being taxed and bonds are being repaid. We come up with quantitative estimates of the key policy effects to demonstrate the effectiveness of green bonds in terms of the emission reduction, the welfare improvement and the intergenerational inequity minimization.

The remainder of the paper is organized as follows. Section 2 introduces an extended DICE model with bonds. Section 3 presents the simulation results comparing several scenarios. Section 4 provides the conclusions. Appendix A contains a complete model description and a reflection on the role of the choice of the climate change damage function.

\section{Model}

The DICE model family ${ }^{3}$ is based on economic growth theory, in which a single good is produced depending on the available production factors. Most commonly, and also in DICE, these are capital and labor. The capital stock accumulates due to investments and

\footnotetext{
${ }^{2}$ When we speak about green bonds, this might also include credit flows from banks, since both represent current borrowing with the promise to pay back in the future.

${ }^{3}$ In our proposed extension of the DICE model we employ the DICE-2013R version (in what follows DICE model); we are aware that the DICE-2016R version has already been issued recently, but to date it has not received yet such a wide spread peer review and recognition as the previous version. Anyway, both models rely on the same equations, only some parameters (e.g., coefficients in the damage function) are calibrated differently, the most recent version claims to rely on more recent data. For more information see (W. D. Nordhaus 2017a).
} 
hence there is a tradeoff between a greater consumption today and investment in capital, which will enable a greater consumption in future. In addition to the economic dynamics, the DICE model also contains a simple representation of the global carbon cycle, climate and economic losses from climate change. The model is global and full participation of the world's GHG emitting nations is assumed. The DICE model illuminates another tradeoff that is the one between a greater investment, more production, higher GHG emissions, more pronounced global warming and hence greater economic losses on the one hand, and a higher abatement, lower economic losses and hence a lower consumption on the other hand. By choosing the investment/saving rate and abatement policies, a policy-maker maximizes the integrated discounted welfare derived from per capita consumption and hence finds an optimal level of global warming and its effects to be accepted, as well as the resultant optimal economic path.

The inclusion of bonds introduces another policy variable, namely, a tax to repay the bonds, together with two further tradeoffs. The first tradeoff is associated with the total amount of bonds to be issued: a larger amount would help ensure a higher emission reduction and hence would also mitigate a larger portion of the climate change losses, but on the other hand it is a larger amount of bonds inflated by the interest rate that will need to be repaid later. The second tradeoff relates to the taxation rate and the duration of the taxation period, during which the bonds should be fully repaid including the interest rate: a lower rate implies a longer repayment period and hence a higher total interest. We show that the additional financial resources, which can be borrowed from future generations in the form of green bonds, might be used to compensate the mitigation costs now. In what follows we present the model equations.

\subsection{Original DICE-2013R model}

In this section, we do not cover all equations of the DICE model, but only the ones necessary to explain the model modification and simulations. Missing equations and all parameter values are given in Appendix A.

The main economic variables of the DICE model are the global capital stock $K(t)$ and the global gross domestic product (GDP) $Y(t)$. The GDP is produced according to the Cobb-Douglas production function $Y(t)=A(t) K^{\gamma}(t) L^{1-\gamma}(t)$. Here $A(t)$ is the total factor productivity, $L(t)$ is the population assumed to be equal to the labor input, and $\gamma$ is the output elasticity of capital. The dynamics of labor and the total factor productivity are modeled independently from the rest of the model (see Appendix A). The net output, that is the GDP net of damages and abatement, is defined by the following formula:

$Q(t)=[1-\Lambda(t)] \Omega(t) Y(t)$

where

$\Omega(t)=\frac{1}{1+a T_{\mathrm{AT}}^{2}(t)}$ 
is the damage multiplier reflecting the damaging effect of rising temperatures on the world GDP ${ }^{4}$; here $T_{\mathrm{AT}}(t)$ is the mean Earth surface temperature increase compared to the temperature in the year 1900. Abatement function $\Lambda(t)$ in (1) represents the fraction of the GDP net of damages, $\Omega(t) Y(t)$, which is allocated to mitigation of the anthropogenic $\mathrm{CO}_{2}$ emissions. It has the interpretation of the abatement cost and is defined based on the emissions reduction rate, $\mu(t) \geq 0$, as follows:

$\Lambda(t)=\theta_{1}(t) \mu^{\theta_{2}}(t)$

with $\theta_{1}(t)$ and $\theta_{2}$ given exogenously (see Appendix A). Importantly, the considered version of the DICE model incorporates a backstop technology, that is a possibility to replace all fossil fuels $(\mu(t)=1)$, as well as negative emissions $(\mu(t)>1)$, which, according to some experts, can become a realistic option in future (Fuss et al. 2014; W. Nordhaus and Sztorc 2013). The DICE-2013R model assumes that negative emissions become a reality starting from the year 2155 .

The model dynamics is defined over a discrete time grid with time step of 5 years. The capital stock accumulates due to investment $I(t)$ :

$K(t+1)=5 I(t)+(1-\delta)^{5} K(t)$,

where $\delta>0$ is an annual depreciation rate of capital.

Finally, industrial $\mathrm{CO}_{2}$ emissions are derived from the produced output and the emission reduction rate as follows

$E_{\text {Ind }}(t)=\sigma(t)[1-\mu(t)] Y(t)$

depending on the exogenously given carbon intensity $\sigma(t)$. Together with the projected land-use emissions $E_{\text {Land }}(t)$ (see Appendix A), they result in total $\mathrm{CO}_{2}$ emissions, $E(t)=$ $E_{\text {Ind }}(t)+E_{\text {Land }}(t)$.

To capture the carbon cycle, the DICE model considers three reservoirs for carbon - the atmosphere, the upper ocean, and the lower ocean - and flows between these reservoirs:

$\left[\begin{array}{l}M_{\mathrm{AT}}(t+1) \\ M_{\mathrm{UP}}(t+1) \\ M_{\mathrm{LO}}(t+1)\end{array}\right]=\left[\begin{array}{c}\xi_{1} \\ 0 \\ 0\end{array}\right] E(t)+\left[\begin{array}{ccc}\phi_{11} & \phi_{12} & 0 \\ \phi_{21} & \phi_{22} & \phi_{23} \\ 0 & \phi_{32} & \phi_{33}\end{array}\right]\left[\begin{array}{l}M_{\mathrm{AT}}(t) \\ M_{\mathrm{UP}}(t) \\ M_{\mathrm{LO}}(t)\end{array}\right]$,

where $M_{\mathrm{AT}}(t), M_{\mathrm{UP}}(t), M_{\mathrm{LO}}(t)$ are carbon stocks in the atmosphere, the upper ocean and the lower ocean. $\mathrm{CO}_{2}$, as well as other GHG gases in the atmosphere create the total radiative forcing that is the difference between the sunlight absorbed by the Earth and the energy radiated back to space. The change in the total radiative forcing relative to the year 1750 due to anthropogenic GHG sources, $F(t)$, is modeled as follows:

$F(t)=\eta \log _{2}\left(\frac{M_{\mathrm{AT}}(t)}{M_{\mathrm{AT}}(1750)}\right)+F_{\mathrm{EX}}(t)$,

\footnotetext{
${ }^{4}$ In Appendix B we discuss the role of the choice of a particular function form to describe the climate change related damages.
} 
where the first term is the radiative forcing change associated with the increase in $\mathrm{CO}_{2}, \eta$ represents forcings of equilibrium $\mathrm{CO}_{2}$ doubling, $F_{\mathrm{EX}}(t)$ is the change in the forcing associated with GHGs other than $\mathrm{CO}_{2}$, given exogenously. A higher radiative forcing warms the atmosphere and, subsequently, the deep ocean as described by the following equations:

$\left[\begin{array}{l}T_{\mathrm{AT}}(t+1) \\ T_{\mathrm{LO}}(t+1)\end{array}\right]=\left[\begin{array}{c}\xi_{2} \\ 0\end{array}\right] F(t+1)+\left[\begin{array}{ll}\zeta_{11} & \zeta_{12} \\ \zeta_{21} & \zeta_{22}\end{array}\right]\left[\begin{array}{l}T_{\mathrm{AT}}(t) \\ T_{\mathrm{LO}}(t)\end{array}\right]$

where $T_{\mathrm{LO}}(t)$ is the temperature increase of lower ocean compared to the temperature in the year 1900 .

In the original DICE model, consumption $C(t)=Q(t)-I(t) \geq 0$ and emission reduction rate $\mu(t) \geq 0$ are policy variables. A policy maker chooses such $C(t)$ and $\mu(t)$ so that to maximize the social welfare function

$W=\sum_{t=1}^{T}(1+\rho)^{-5(t-1)} L(t) \frac{c^{1-\alpha}(t)}{1-\alpha}$

where $c(t)=C(t) / L(t)$ is per capita consumption and $\alpha$ is an elasticity of the instantaneous utility of consumption, $\rho$ is the annual social time preference, which sometimes is referred to as the discount rate ${ }^{5}$. The time horizon $T$ in (9) is fixed ${ }^{6}$.

\subsection{Augmented DICE model: Green bonds}

In this section we introduce green bonds that is a flow of borrowed capital to be used to finance mitigation costs. We make three major assumptions. First, we assume that bonds should cover the mitigation costs. Partial coverage can be modeled similarly, but we prefer to avoid this technical complication in this paper.

Second, we assume that capital can be borrowed from outside of the economy under consideration and hence we do not count bonds as a part of the households' wealth. Normally, when modeling the issuing of bonds arising from government excess spending over income (tax revenue), this debt is treated as an inside debt. Thereby households become inside debt holders splitting their asset investment and asset holdings between real capital and bonds. Then the government budget constraint is to be introduced into the household budget constraints and government spending effects on growth and future output is to be considered.

Under assumptions that i) the government spending has no productive effects and ii) the tax is a lump sum tax, there is no real effect on the capital stock and output regardless of the way by which the government finances its spending - by taxation or by issuing bonds. This is what economists call the Ricardian equivalence theorem (RET) that states that the two ways of financing the government spending are equivalent. ${ }^{7}$

\footnotetext{
${ }^{5}$ A discussion of which values of the discount rate are appropriate to be used to generate long-term scenarios and their justification can be found in (W. Nordhaus 2008).

${ }^{6}$ Neoclassical economic growth models are often considered over the infinite time horizon. However, here we follow the DICE convention and solve the intertemporal model over a finite horizon, taking $T$ long enough and ignoring the time period of last 50 years when the policy maker decides to consume the entire output and investment becomes senseless in anticipation of the end of the simulation period.

${ }^{7}$ As to inside debt, as Tobin has already argued, the wealth of a nation (for example bond holdings of domestic households) is not increased when it issues liabilities against itself.
} 
Notably, the challenges of the RET do not hold in our case, since both assumptions i) and ii) do not hold. Hence, we could employ a Tobin-like macroeconomic portfolio approach with equity and bonds as assets, and our approach would also be consistent with the inside debt issued by the government. ${ }^{8}$ This would require however a lengthy treatment of the interaction of portfolio decisions, shifting asset holdings and the impact on the real side of the economy, the evolution of capital stock and output. On the other hand, the non-mitigated damages occurring on the real side would affect the asset value of the capital stock entailing some further portfolio decisions. In order to avoid these complications, we here treat the debt as an outside debt and our debt holders are external creditors. Thus, in our short cut here, the treasury bonds are sold to foreign entities, and then repaid later, as modeled in (Blanchard and Fischer 1989). Yet the mechanism of mitigation-reimbursement-repayment of bond scheme is the same as for inside debt. ${ }^{9}$

Third, we assume that the external debt on green bonds is repaid via a specially introduced green tax. In principle, the green tax is introduced at the same moment of time as the green bonds are issued. The amount of green bonds, their issuing in excess of tax revenue, their maturity, as well as the period of their repayment are to be defined endogenously by the model.

Let $\tau(t) \in[0,1]$ be a time-dependent green tax 'rate', i.e., a share of the net GDP. We supplement the original DICE-2013R model with an equation that describes dynamics of the green bond stock $B(t)$ as follows

$B(t+1)=\left(1+r_{\mathrm{B}}\right)^{5} B(t)+5(\Lambda(t)-\tau(t)) \Omega(t) Y(t)$,

where $r_{\mathrm{B}}$ is a fixed one-year green bond interest rate. Similar equations are used in (Blanchard and Fischer 1989; Nishimura et al. 2015). In order not to have a Ponzi scheme in the model, we require that at the end of the model's time horizon all bonds are repaid so that the intertemporal budget constraint holds, i.e., $B(T)=0$. Also, we assume the initial condition $B(1)=0$, supposing that there is no governmental debt at the beginning.

Mitigation and taxation start at the same time that is at the beginning of our simulation period. However, we expect that, at the beginning, the mitigation costs are growing faster and accumulate, and only after a while taxation actually takes off. In the time period of excess mitigation cost over taxation, the mitigation costs are paid via bonds, and the green tax is levied on the net GDP. Hence, we rewrite equation (1) for the net output as follows:

$Q(t)=[1-\tau(t)] \Omega(t) Y(t)$.

This change affects capital dynamics (4) via investment $I(t)$ which is a part of $Q(t)$, i.e., $I(t)=Q(t)-C(t)$. With modifications defined by equations (10) and (11), we obtain the "modified DICE model".

So, the abatement costs are fully covered by bonds, which are repaid later by taxation. Note that in our model the bond interest rate is constant over time and is different

\footnotetext{
${ }^{8}$ This is planned in a future extension of this paper along the line of a dynamic portfolio approach as presented in (Chiarella et al. 2016, chs 4-6).

${ }^{9}$ We hereby could argue that advanced countries with piled up current account surplus, for example, a country like Germany could be creditors.
} 
from the return on capital, which is time-dependent ${ }^{10}$. This is in contrast with the Sachs's approach where the bond interest rate is the same as the capital return. This is usually also assumed in the RET. ${ }^{11}$

Notably, in (11) we have a distortionary product tax to pay for the activities of removing externalities and the tax distortions could be smoothed over time, see (Lucas and Stokey 1983) who discuss in detail the issue of time inconsistency that might arise in this context. The bond issuing can accelerate the climate policy, the tax distortions can be smoothed and the maturity structure of bonds could be changed, without necessarily having a time inconsistent fiscal policy, see (Lucas and Stokey 1983), who argue that governments in the future are free to set tax rates and the maturity structure of debt but need to commit to debt payments. The tax rate $\tau(t)$ is endogenous in our model - in contrast with previous works (Flaherty et al. 2016; Sachs 2015) where the tax path was pre-defined. Moreover, in both (Flaherty et al. 2016; Sachs 2015) the phase of bond issuance is separated from the phase of bond repayment. In the present model, taxation is defined based on the maximization of the social welfare function (1) over all phases and the phases of bond issuing and bond repayment, similar to those in (Flaherty et al. 2016), emerge endogenously.

\subsection{Scenarios to be analyzed}

Using this modification of the DICE model, we intend to explore how bonds can help to resolve the issue of intergenerational fairness, whether they can enhance the acceptability of mitigation actions, and to what extent and when the GHG emissions can be abated. In order to do so, we compare five scenarios.

The first two scenarios are implemented as in the original DICE model; we call them "No mitigation" (NM) and "Optimal mitigation" (OM). The NM scenario (corresponds to "Optimal” scenario in the DICE model (W. Nordhaus and Sztorc 2013)) implies no mitigation effort, $\mu(t) \equiv 0$ for all time moments $t=1, \ldots, T$; the social planner chooses consumption $C(t)$ so that to maximize the social welfare function (9). In the OM scenario (corresponds to the business-as-usual (baseline) scenario (Flaherty et al. 2016; Sachs 2015)), the social planner chooses both $C(t)$ and $\mu(t)$ to maximize the social welfare function (9).

Further to these, we introduce the "Optimal mitigation with bonds" (OMB) scenario, in which, bonds are introduced and in addition to $C(t)$ and $\mu(t)$, the policy maker also chooses the green tax rate $\tau(t)$ to maximize the social welfare function (9).

To introduce two more scenarios, we define a truncated social welfare function (TSWF) as follows

\footnotetext{
${ }^{10}$ With this simplification, which is also used by (Andersen, Bhattacharya, and Liu 2016), one can bypass the complications that would arise using inside debt: namely keeping track of two types of inside assets, there possibly different returns, and the (possibly two different) tax rates on the different assets.

${ }^{11}$ This is another reason why we bypass the portfolio approach for the time being: In our model not only has government spending a productive effect (removing future externalities), but given a wealth portfolio with different returns on assets and a dynamic asset rebalancing would complicate the tax treatment, to reimburse the bonds, quite significantly.
} 
$W(t)=\sum_{s=1}^{t}(1+\rho)^{-5(s-1)} L(s) \frac{c^{1-\alpha}(s)}{1-\alpha}$.

We say that scenario $i$ is a Pareto improvement of social welfare with respect to scenario $j$ if $W^{i}(t) \geq W^{j}(t)$ for all $t=1, \ldots, T-1$, and $W^{i}(T)>W^{j}(T)$. Since $L(t)$ is monotonically growing and modeled independently from any scenario, the Pareto improvement definition is equivalent to: $C^{i}(t) \geq C^{j}(t), t=1, \ldots, T$, and there exists a $t^{*}$, such that $C^{i}\left(t^{*}\right)>C^{j}\left(t^{*}\right)$.

As will be shown below in Sections 3.1 and 3.2, contrary to what one might expect based on the results by Sachs and Andersen et al., the OM and OMB scenarios do not provide a Pareto improvement of social welfare with respect to the NM scenario. To enable the Pareto improvement, we add extra constraints on consumption in the model. Namely, let us denote by $C^{\mathrm{NM}}(t)$ the optimal consumption path in the NM scenario and introduce the "Pareto optimal mitigation" (POM) scenario in which constraint $C(t) \geq$ $C^{\mathrm{NM}}(t), t=1, \ldots, T$ is added to the social welfare maximization problem. As stated above, the optimal path in such model will, by definition, be a Pareto improvement of social welfare with respect to the NM scenario. Similarly, we construct the "Pareto optimal mitigation with bonds” (POMB) scenario.

\subsection{Calibration and simulations}

Appendix A contains the full list of parameters values used in simulation. We preserve all parameter values from the original DICE-2013R model as they are, except the time horizon of the simulation, which we extend up to 500 years, instead of 300 years as in the original DICE-2013R ${ }^{12}$.

The bond equation (10) contains a new parameter - the annual bond's interest rate $r_{\mathrm{B}}$. In Sections 3.1 and 3.2 we use the value $r_{\mathrm{B}}=3 \%$ for comparison of all five scenarios, which is close to the interest rates of some long-term green bonds issued recently ${ }^{13}$. Further, in Section 3.2 a sensitivity analysis of the results with respect to $r_{\mathrm{B}}$ is provided that reveals that $r_{\mathrm{B}}$ significantly influences the volume of issued bonds as well as the length of the time of repayment. Also in Section 3.2, we discuss why using a constant interest rate makes sense in this modeling exercise.

We run our simulations with the modified DICE-2013R model in GAMS software. We take the original code DICE2013R_110513_vanilla.gms ${ }^{14}$ and amend it according to the introduced modifications (see above). The code files of all five scenarios

\footnotetext{
12 This is to show that due to the possibility of negative emissions, the carbon level can be stabilized down to pre-industrial and to ensure that the effects of the finite time horizon apparent at the end of the simulation period are not visible.

${ }^{13}$ See, for instance, https://www.ft.com/content/db5b911e-508a-11e7-bfb8-997009366969 [Accessed

22.11.2017] and https://www.thenational.ae/business/markets/nbad-green-bond-issuance-putsenvironment-at-forefront-1.9984 [Accessed 22.11.2017]

${ }^{14}$ https://github.com/psztorc/DICE/blob/master/models/gams/DICE2013R 110513_vanilla.gms [Accessed 22.11.2017] and http://www.econ.yale.edu/ nordhaus/homepage/Web-DICE-2013-April.htm [Accessed 25.09.2017]
} 
can be found in supplementary materials. We use the CONOPT solver ${ }^{15}$ to find the solution of the model for each scenario.

\section{Results}

\subsection{Intergenerational problem in DICE-2013R}

We first run the standard scenarios of DICE-2013R model (NM and OM) to demonstrate the intergenerational problem. Consider red curves in Figure 1. The red solid curve represents the relative difference of the TSWF in the OM scenario w.r.t. the TSWF in the NM scenario: $\left[W^{\mathrm{OM}}(t)-W^{\mathrm{NM}}(t)\right] / W^{\mathrm{NM}}(t)$. From the beginning of simulation until the year 2115, the social welfare in the OM scenario is lower than the social welfare in the NM scenario (the curve lies below zero) and only after the year 2115, the social welfare in the OM scenario becomes higher than the social welfare in the NM scenario (the curve lies above zero).

Indeed, this confirms that generations living between now and 2115 would have to accept a lower welfare if an optimal mitigation policy were to be implemented, compared to the case of no abatement. This is because the abatement costs are to be subtracted from consumption and the avoided climate change losses are still too small to overweigh the mitigation costs. Conversely, future generations living beyond the year 2115 would enjoy a higher welfare due to avoided climate change losses; moreover, the welfare gain is only increasing with time.

\subsection{Bonds shorten the period of welfare sacrifice}

The dash-dot red line on Figure 1 represents the relative difference of the TSWF in the OMB scenario w.r.t. the TSWF in the NM scenario: $\left[W^{\mathrm{OMB}}(t)-W^{\mathrm{NM}}(t)\right] / W^{\mathrm{NM}}(t)$. Again, in the first period generations sacrifice a part of their welfare and redirect a fraction of their consumption to abatement, while in the second period future generations enjoy a higher welfare. Thanks to bonds, which also contribute to the abatement effort, the fraction to be taken out from current consumption for mitigation, becomes smaller and hence bonds offer a Pareto improvement to the OM scenario (the dash-dot red curve lies entirely above the red solid curve). Despite the welfare sacrifice period gets shortened by 30 years and lasts only until the year 2085, bonds alone are not able to deliver a Pareto improvement w.r.t. NM scenario.

\footnotetext{
15 Since the resultant optimization problem is not concave, one cannot guarantee that the solution found numerically is globally optimal. We carried out several experiments with different initial values for the NLP solver and always arrived at the same solution, which suggests that it may indeed be globally optimal; furthermore, we refer to (W. Nordhaus 2008) where it is also claimed that other solutions (other than optimal scenario, corresponding to our OM scenario, and business-as-usual scenario, corresponding to our NM scenario) have not been found yet.
} 


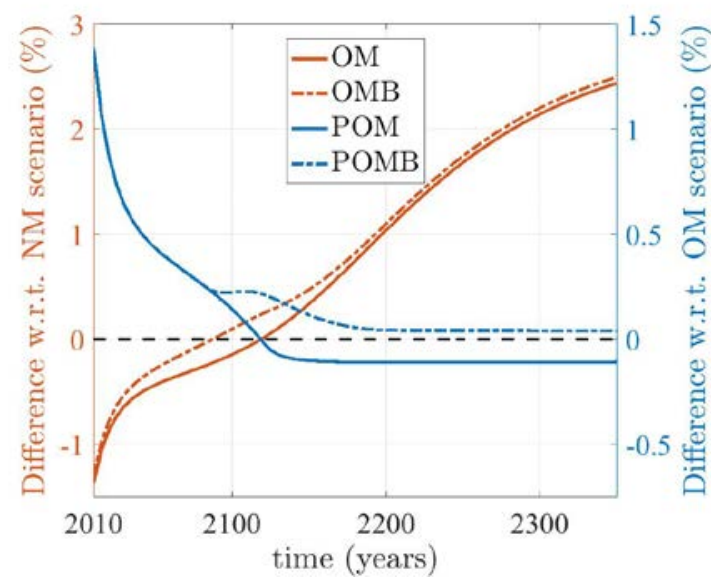

Figure 1. Percentage difference in TSWF w.r.t. NM and OM scenarios

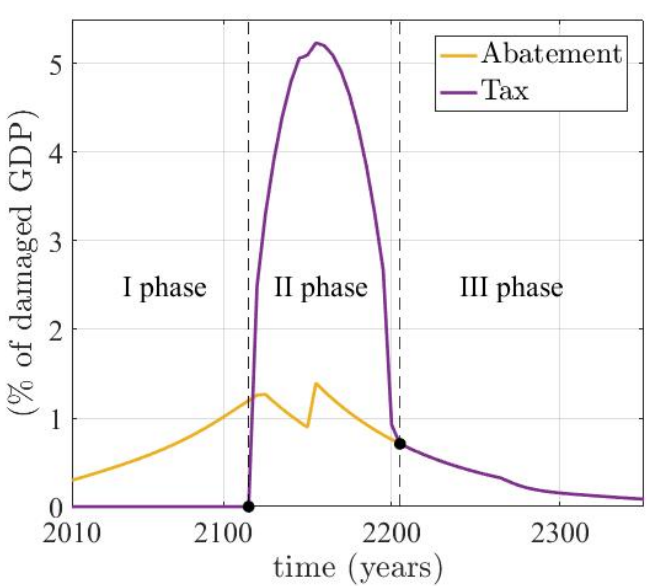

Figure 2. Abatement part and tax part of GDP net of damages (three phases, OMB scenario)

Despite both green bonds and green tax are allowed throughout the entire simulation period, in the optimum, three distinct phases emerge endogenously: (I) bond issuance (2010-2115), (II) bond repayment (2120-2200), and (III) taxation for mitigation (2205 onwards). Figure 2 illustrates these phases by showing the green bond and green tax fractions of the net output. In phase I, green tax zero, and abatement is positive reaching $1.2 \%$ of GDP by the year 2115 . In our model, abatement is fully financed by bonds and hence the governmental debt accumulates. Since the social planner optimizes an integral welfare function over the entire simulation period, she anticipates the repayment of bonds in future and decreases consumption in phase I. This releases additional funds for investment, thanks to which the future output increases and bonds can be repaid then in phase II without sacrificing consumption. This preference to reduce consumption in phase I instead of phase II is due to a lower bond's interest rate vis-à-vis the capital return rate adjusted based on the discount rate. Let us point here that this result contrasts with the result by (Sachs 2015) who used a piecewise welfare functions, a separate one for each generation and hence in his model the current generation experienced no net burden.

Phase II combines green tax, bond issuance and bond repayment. Hence the tax rate must be higher than the abatement rate reaching up to 5\% of the GDP. By the end of phase II, bonds are fully repaid. In phase III mitigation is funded by green tax only, it is not optimal to use green bonds anymore. Thus, overall our results roughly replicate the structure of the intertemporal fiscal policy introduced by (Sachs 2015) and further investigated by (Flaherty et al. 2016). In Appendix C, we examine the robustness of this conclusion with respect to the choice of the damage function.

\subsection{Pareto-optimal mitigation possible}

Here we analyze the POM and POMB scenarios, which are modifications of the OM and OMB scenarios correspondingly, such that the consumption levels are forced to levels ensuring a Pareto improvement w.r.t. NM scenario in each case, as the blue curves at Figure 1 demonstrate. 
Namely, the blue solid curve represents the relative difference of the TSWF in the POM scenario w.r.t. the TSWF in the NM scenario: $\left[W^{\mathrm{POM}}(t)-W^{\mathrm{OM}}(t)\right] / W^{\mathrm{OM}}(t)$. While by construction, the POM scenario is Pareto-improving w.r.t. the NM scenario, it is not Pareto-improving w.r.t. the OM scenario as the POM scenario is optimal in the same NLP problem as the OM scenario but with additional constraints $C(t) \geq C^{\mathrm{NM}}(t)$. By same argument the POMB scenario is not Pareto-improving w.r.t. the OMB scenario.

The dash-dot blue curve represents the relative difference of the TWSF in the POMB scenario w.r.t. the TSWF in the OM scenario: $\left[W^{\mathrm{POMB}}(t)-W^{\mathrm{OM}}(t)\right] / W^{\mathrm{OM}}(t)$. The curve lies entirely above zero, which demonstrates that the POMB scenario provides a Pareto-improvement not only w.r.t. the NM scenario, but also w.r.t. the OM scenario. In addition, the POMB scenario is also Pareto-improving w.r.t. the POM scenario (the dash-dot blue curve lies entirely above the blue solid curve).

\subsection{Mitigation success and climate change damages}

In this section we analyze how effective the abatement policy is in each considered scenario. We focus on two key interconnected indicators: Carbon amount in the atmosphere (Figure 3) and economic damages (Figure 4).

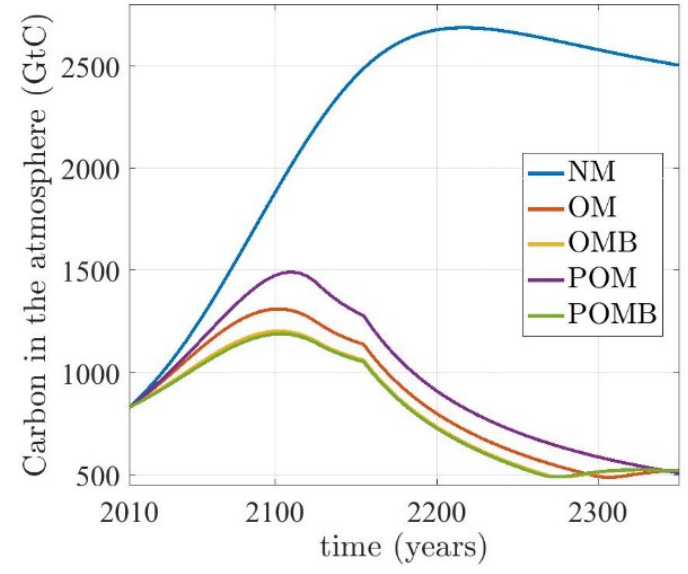

Figure 3. Atmospheric carbon in Gt C (all scenarios)

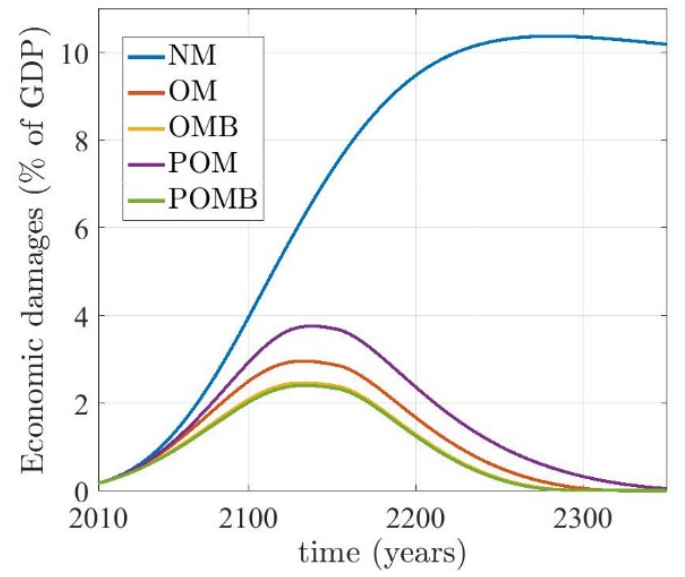

Figure 4. Damages to GDP in per cents (all scenarios)

In the NM scenario the carbon concentration in the atmosphere grow over time from $830.4 \mathrm{Gt} \mathrm{C}$ in the year 2010 reaching the peak of about $2700 \mathrm{Gt} \mathrm{C}$ in the year 2215. It aggravates global warming so that the economic damages from climate change reach as much as about $10 \%$ of the GDP in the year 2215. Such significant negative economic impacts decrease industrial production, which leads to a slight decrease of the GHG emissions and carbon concentration in the atmosphere from the year 2215 onwards.

Clearly, such path is not sustainable, eventually it implies low social welfare function values, and hence the social planner operating on a reasonably long time horizon has an incentive to mitigate. All mitigation scenarios, with or without bonds, converge to the equilibrium level of carbon in the atmosphere (roughly $520 \mathrm{Gt} \mathrm{C}$ ) and zero climate change damages. This transition takes about 300 years and happens without any terminal condition on the atmospheric carbon amount, that is it is actually optimal in terms of the social welfare function to avoid the climate change effects entirely. 
Notably, the convergence to the pre-industrial GHG level is only possible due to the possibility of negative emissions in the model. We ran a test experiment in which no negative emissions were possible. In this case, the carbon concentration in the atmosphere in the OM scenario peaked at $1300 \mathrm{Gt} \mathrm{C}$ and then decreased down to as much as $1000 \mathrm{Gt}$ $\mathrm{C}$ at the end of simulation period (the year 2510).

Further, the trajectories of the OMB and POMB scenarios (yellow and green respectively) roughly coincide and provide the fastest convergence and lowest maximum level of atmospheric carbon and of the maximal damages to GDP. Hence, bonds are both effective and efficient mechanism to finance mitigation.

Contrary to this, the POM scenario is significantly less effective in reducing carbon than its original version, the OM scenario. This is because the increase in consumption to the levels of the NM scenario, forced at the beginning of the simulation period, leaves a smaller part of the GDP available for abatement, which leads to higher emissions and a slower transition to a carbon free economy.

\subsection{Sensitivity analysis w.r.t. the bond's interest rate}

In the results presented above, the bond's interest rate, representing the yields on bonds, was fixed at a constant level of 3\% per annum. Note that the bond interest rate should be greatly affected by the risk premium. Our model does not contain an explicit bond market, instead the bond interest rate is given exogenously. In this section we would like to study the effects of varying the bond interest rate, reflecting possibly different risk premia and other factors, on our results.

Note that in Sachs model (2015), the bond interest rate is equal to the interest rate of capital, which is kept at the same level in the OLG model. In the Ramsey-type models, including the DICE model, the capital return is dynamic. Relying on the recent overview on interest rates and maturities of green bonds by (Flaherty et al. 2016), we choose five alternative values of interest rate of bonds: $r_{\mathrm{B}}=2.5 \%, 3 \%, 3.5 \%, 4 \%, 4.5 \%$ and investigate the corresponding sensitivity of the OMB scenario.

Figure 5 presents the bonds-to-GDP (GDP net of damages) ratio for the chosen alternative interest rates. Lower interest rates of bonds naturally lead to higher maximal government debt and to longer duration of phase I and phase II in which bonds are used to finance abatement. The interest rate of $r_{\mathrm{B}}=4.5 \%$ is indeed high: bonds are used in a very limited way, the maximal debt reaches only $3 \%$ of the net-of-damages GDP and it takes only 35 years until they are repaid. Conversely, the interest rate of $r_{\mathrm{B}}=2.5 \%$ is indeed rather low: bonds are now used very intensely, the maximal debt goes up as high as $400 \%$ of the net-of-damages GDP and it takes 300 years until they are repaid.

Figure 6 illustrates the difference in the optimal green tax rate corresponding to the considered five values of the bonds interest rate. The higher is the interest rate, the longer is the duration of the taxation period - 15 years in case of $r_{\mathrm{B}}=4.5 \%$ vis-à-vis about 150 years in case of $r_{\mathrm{B}}=2.5 \%$. Also, the higher the interest rate is, the greater is the maximal level of taxation $-1.4 \%$ of the net-of-damages GDP in case of $r_{\mathrm{B}}=4.5 \%$ vis-à-vis $10.6 \%$ of the net-of-damages GDP in case $r_{\mathrm{B}}=2.5 \%$. 


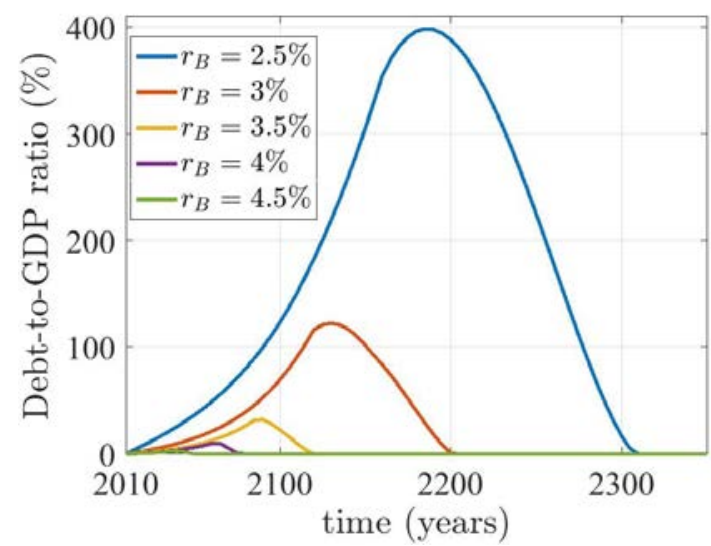

Figure 5. Bonds to GDP net of damages ratio in per cents (OMB scenario)

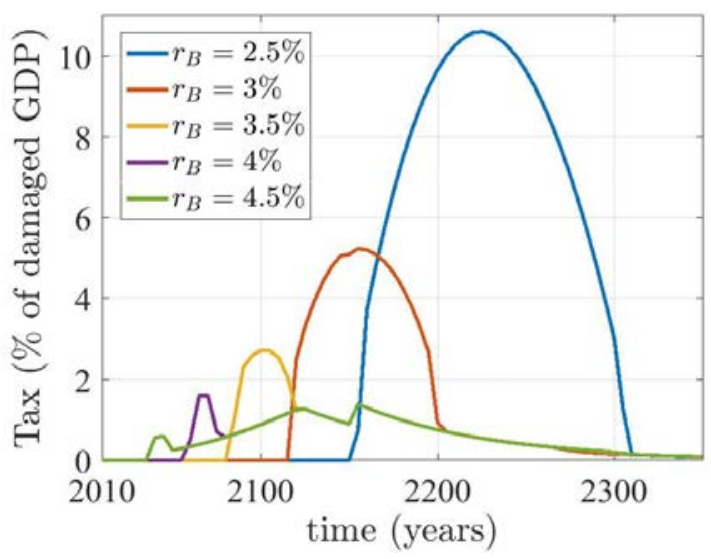

Figure 6. Tax part of GDP net of damages in per cents (OMB scenario)

Consequently, lower interest rates on bonds lead to a more extensive use of bonds, which enables a faster convergence of atmospheric carbon to the equilibrium level, a lower maximal level of carbon in the atmosphere, smaller damages to the GDP, and, finally, a higher overall social welfare.

\section{Conclusions and discussion}

Clearly, despite all scientific evidence, at the present time politicians in many countries are reluctant to be motivated to invest in climate change mitigation because they do not see adverse consequences of global warming, which are anticipate to become much more pronounced in the future. For an economy with a long lasting negative externality, showing up in a slowly moving trend of temperature increase, climate change and damages, the mitigation effort is a corrective measure, which can be incentivized by a carbon price/tax. A higher price of fossil fuels due to carbon tax, and a consequent lower use of fossil fuels should eventually lead to substituting away from fossil fuels. Yet, many climate economists currently presume that the carbon tax may not rise over time, and the effect on the transition to a low-carbon economy may not be sufficient since this process may be too slow. In addition, the fossil fuel price is quite volatile and hence the presumed nexus between the carbon tax and de-carbonization of the economy cannot be empirically established easily. Many economists are of the opinion that some complementary measures are needed such tighter regulation, directed technical change to a new energy systems, and large-scale climate investments (Bonen et al. 2016). In the absence of such measures, intergenerational equity as a natural behavioral law may establish temporal justice as a prerequisite of sustainable development (Puaschunder 2017).

Along these lines, in this paper we have explored the combined measures of carbon tax and climate bonds, both to incentivize as well as to scale up the finance the transition to a low-carbon economy. We have proposed here a scalable solution, namely to extensively introduce green bonds and to apply inter-temporal sustainable fiscal policy to accelerate climate stabilization. This strategy not only seems to be politically more feasible than a higher tax spike for speeding up climate control, but it also appears to be more preferable in terms of intergenerational burden sharing and welfare improvements. Concerning the financial market, given the currently observed low interest rate environment, and in the search for some stable long run returns, one can find green bonds 
an attractive option ((Flaherty et al. 2016) used econometric analysis to discuss the possibility of bonds phasing into current macroeconomic environment).

We have evaluated the feasibility of green bonds in combination with carbon tax in the DICE-2013R modeling framework that in the stylized fashion, arguably, is the most up-to-date model comprising the entire causal loop of economic growth, GHG emissions, temperature increase and corresponding global warming related economic damages. We have demonstrated that from the social welfare maximization perspective the three phases emerge - mitigation scaled up by bond financing, bond repayment via carbon tax, and mitigation financed by carbon tax. The climate bond solution has been shown to smoothen out distortionary taxation without running necessarily into the Ricardian equivalence problem.

The interest rate on bonds has been found to influence strongly the amount of issued bonds. A lower interest rate therefore significantly accelerates the transition to a low-carbon economy. Since currently we observe exceptionally low interest rates, the introduction of green bonds might be very timely to pursue climate mitigation.

Previous studies, which examined possible effects of green bonds for climate mitigation, (Sachs 2015), (Andersen, Bhattacharya, and Liu 2016), and (Flaherty et al. 2016), laid down the foundation for this paper. DICE-2013R is a more detailed and holistic model than any in these studies, and it is perhaps the most accepted and influential one in the class of stylized IAMs, used also for advising to policy. Applying green bonds in DICE is therefore a good test of their feasibility in real policy decisions. Our results have suggested a less optimistic picture than the previous works painted. If the policy maker aims at improving the social welfare function, bonds alone are not able to completely eliminate the intergenerational inequities. An additional compensation mechanism redistributing consumption over generations is necessary to ensure that all generations are not worse-off as a result of mitigation efforts.

The results presented in this paper are derived from the global DICE model with no geographical heterogeneity. In reality, different regions of the world and the GDP prospects in different parts of the globe are affected differently by a warming globe. A more sophisticated 3-dimensional climate justice mandate may thus ensure to distribute the gains and losses of climate change fair within a society, between countries of the world and over time in between generations (Puaschunder 2017).

Our study rests on one important simplifying assumption, namely, we have assumed the bond debt to be external debt. While in lights of the arguments in Section 2.2 we anticipate that it should not affect the main findings, as a next step we would like to explore it rigorously and consider an inside debt explicitly. For that, we will need to reformulate the debt dynamics and use a portfolio approach in which rebalancing of the portfolio between bonds and capital investments when relative returns (or risks) change should be possible (see (Chiarella et al. 2016, chs 4-7)).

\section{References}

Andersen, T. M., Bhattacharya, J., and Liu, P., 2016. "Resolving Intergenerational Conflict over the Environment under the Pareto Criterion.” 6053. CESifo Working Paper Series. CESifo Group Munich. https://ideas.repec.org/p/ces/ceswps/_6053.html. 
Baranzini, A., Goldemberg, J., and Speck, S., 2000. "A Future for Carbon Taxes.” Ecological Economics 32 (3):395-412. https://doi.org/10.1016/S0921-8009(99)00122-6.

Blanchard, O.J., Fischer, S., 1989. Lectures on Macroeconomics. MIT Press.

Bonen, A., Loungani, P., Semmler, W., and Koch, S., 2016. "Investing to Mitigate and Adapt to Climate Change; A Framework Model.” IMF Working Paper No. 16/164. International Monetary Fund. https://ideas.repec.org/p/imf/imfwpa/16-164.html.

Chiarella, C., Semmler, W., Hsiao, C-Y., and Mateane, L., 2016. Sustainable Asset Accumulation and Dynamic Portfolio Decisions. Dynamic Modeling and Econometrics in Economics and Finance 18. Springer-Verlag Berlin Heidelberg. http://www.springer.com/us/book/9783662492284.

Flaherty, M., Gevorkyan, A., Radpour, S., and Semmler, W., 2016. "Financing Climate Policies through Climate Bonds - A Three Stage Model and Empirics." Research in International Business and Finance. https://doi.org/10.1016/j.ribaf.2016.06.001.

Fuss, S., Canadell, J.G., Peters, G.P., Tavoni, M., Andrew, R.M., Ciais, P., Jackson, R.B., et al. 2014. "Betting on Negative Emissions." Nature Climate Change 4 (10):850-53. https://doi.org/10.1038/nclimate2392.

Government Accountability Office. 2014. "Regulatory Impact Analysis: Development of Social Cost of Carbon Estimates.” GAO-14-663. DC: GAO.

High-Level Commission on Carbon Prices. 2017. "Report of the High-Level Commission on Carbon Prices." World Bank. Washington, DC: World Bank. https://www.carbonpricingleadership.org/report-of-the-highlevel-commission-oncarbon-prices/.

Kato, M., Mittnik, S., Samaan, D., and Semmler, W., 2015. "Employment and Output Effects of Climate Policies,” January. https://doi.org/10.1093/oxfordhb/9780199856978.013.0019.

Kellett, C.M., Faulwasser, T., and Weller, S.R., 2016. “DICE2013R-Mc: A Matlab / CasADi Implementation of Vanilla DICE 2013R.” arXiv:1608.04294 [math], August. http://arxiv.org/abs/1608.04294.

Kimble, J.J., 2006. Mobilizing the Home Front: War Bonds and Domestic Propaganda. Texas A\&M University Press.

Kindleberger, C.P., 1985. A Financial History of Western Europe. London Allen \& Unwin. http://trove.nla.gov.au/work/19968265. 
Lucas, R.E., and Stokey, N.L., 1983. "Optimal Fiscal and Monetary Policy in an Economy without Capital.” Journal of Monetary Economics 12 (1):55-93. https://doi.org/10.1016/0304-3932(83)90049-1.

Marron, D.B., and Morris, A.C., 2016. "How to Use Carbon Tax Revenues." https://papers.ssrn.com/sol3/papers.cfm?abstract_id=2737990.

Metcalf, G., and Stock, J., 2015. "The Role of Integrated Assessment Models in Climate Policy: A User's Guide and Assessment.” Harvard Project on Climate Agreements, Belfer Center, 2015. http://www.belfercenter.org/publication/role-integratedassessment-models-climate-policy-users-guide-and-assessment.

Nishimura, K., Nourry, C., Seegmuller, T., and Venditti, A., 2015. "On the (de)stabilizing Effect of Public Debt in a Ramsey Model with Heterogeneous Agents.” International Journal of Economic Theory 11 (1):7-24. https://doi.org/10.1111/ijet.12049.

Nordhaus, W., 2008. A Question of Balance: Weighing the Options on Global Warming Policies. Yale University Press. http://www.jstor.org/stable/j.ctt1npzkh.

Nordhaus, William D. 2017a. "Revisiting the Social Cost of Carbon." Proceedings of the National Academy of Sciences of the United States of America 114 (7):1518-23. https://doi.org/10.1073/pnas.1609244114.

2017b. "Evolution of Assessments of the Economics of Global Warming: Changes in the DICE Model, 1992 - 2017.” Working Paper 23319. National Bureau of Economic Research. http://www.nber.org/papers/w23319.

Nordhaus, W., and Sztorc, P., 2013. DICE 2013R: Introduction and User's Manual. Second. New Haven, CT: Cowles Found.

Poterba, J.M., 1991. “Tax Policy to Combat Global Warming: On Designing a Carbon Tax.” Working Paper 3649. National Bureau of Economic Research. http://www.nber.org/papers/w3649.

Puaschunder, J.M., 2017. "Sunny Side Up! From Climate Change Burden Sharing to Fair Global Warming Benefits Distribution: Groundwork on the Metaphysics of the Gains of Global Warming and the Climatorial Imperative.” SSRN Scholarly Paper ID 2931302. Rochester, NY: Social Science Research Network. https://papers.ssrn.com/abstract=2931302.

Sachs, J.D., 2015. “Climate Change and Intergenerational Well-Being.” In The Oxford Handbook of the Macroeconomics of Global Warming, edited by Lucas Bernard and Willi Semmler. Oxford University Press. http://www.oxfordhandbooks.com/view/10.1093/oxfordhb/9780199856978.001.0001/o xfordhb-9780199856978-e-011. 
Schleussner, C.-F., Lissner, T.K., Fischer, E.M., Wohland, J., Perrette, M., Golly, A., Rogelj, J., et al. 2016. "Differential Climate Impacts for Policy-Relevant Limits to Global Warming: The Case of $1.5{ }^{\circ} \mathrm{C}$ and $2{ }^{\circ} \mathrm{C} . "$ Earth Syst. Dynam. 7 (2):327-51. https://doi.org/10.5194/esd-7-327-2016.

Semmler, W., Greiner, A., Diallo, B., Rajaram, A., and Rezai, A., 2011. "Fiscal Policy, Public Expenditure Composition and Growth: Theory and Empirics." The IEB International Journal of Finance, July 2011.

Stern, N., 2008. "The Economics of Climate Change.” The American Economic Review 98 (2):1-37. https://doi.org/10.2307/29729990.

“The World Economic Forum Report.” 2015. Davos, Switzerland: World Economic Forum. http://wef.ch/1Hk0iGG.

Wouter Botzen, W. J., Jeroen C. J., and van den Bergh, M., 2012. "How Sensitive Is Nordhaus to Weitzman? Climate Policy in DICE with an Alternative Damage Function." Economics Letters 117 (1):372-74. https://doi.org/10.1016/j.econlet.2012.05.032.

\section{Appendix}

\section{A DICE-2013R model full description}

This part is written based on the GAMS code and (W. Nordhaus and Sztorc 2013; Kellett, Faulwasser, and Weller 2016). Below there are all equations of DICE-2013R model generating Optimal mitigation scenario ${ }^{16}$. Let us note that the conversion between parameter $t$ in the DICE-2013R model and the corresponding year can be done via the following formula: year $=2010+5(t-1)$.

$\operatorname{Maximize}_{s(\cdot), \mu(\cdot)} W=\sum_{t=1}^{T} R(t) U(c(t), L(t))$

subject to

$K(t+1)=5 I(t)+(1-\delta)^{5} K(t)$,

$\left[\begin{array}{l}M_{\mathrm{AT}}(t+1) \\ M_{\mathrm{UP}}(t+1) \\ M_{\mathrm{LO}}(t+1)\end{array}\right]=5\left[\begin{array}{c}\xi_{1} \\ 0 \\ 0\end{array}\right] E(t)+\left[\begin{array}{ccc}1-\phi_{12} & \phi_{21} & 0 \\ \phi_{12} & 1-\phi_{21}-\phi_{23} & \phi_{32} \\ 0 & \phi_{23} & 1-\phi_{32}\end{array}\right]\left[\begin{array}{l}M_{\mathrm{AT}}(t) \\ M_{\mathrm{UP}}(t) \\ M_{\mathrm{LO}}(t)\end{array}\right]$,

$T_{\mathrm{AT}}(t+1)=T_{\mathrm{AT}}(t)+\zeta_{1}\left\{F(t+1)-\frac{\eta}{\zeta_{2}} T_{\mathrm{AT}}(t)-\zeta_{3}\left[T_{\mathrm{AT}}(t)-T_{\mathrm{LO}}(t)\right]\right\}$,

$T_{\mathrm{LO}}(t+1)=T_{\mathrm{LO}}(t)+\zeta_{4}\left[T_{\mathrm{AT}}(t)-T_{\mathrm{LO}}(t)\right]$,

${ }^{16}$ Note that No mitigation scenario can be obtained if one puts $\mu(t) \equiv 0,1 \leq t \leq T$. 
$K(1)=K^{1}, M_{\mathrm{AT}}(1)=M_{\mathrm{AT}}^{1}, M_{\mathrm{UP}}(1)=M_{\mathrm{UP}}^{1}, M_{\mathrm{LO}}(1)=M_{\mathrm{LO}}^{1}, T_{\mathrm{AT}}(1)=T_{\mathrm{AT}}^{1}, T_{\mathrm{LO}}(1)=$ $T_{\mathrm{LO}}^{1}$,

$0 \leq \mu(t) \leq 1, t=2, \ldots, t_{\mu}-1$,

$0 \leq \mu(t) \leq 1.2, t=t_{\mu}, \ldots$,

$\mu(1)=\mu^{1}$.

Here

$R(t)=(1+\rho)^{-5(t-1)}$,

$U(c(t), L(t))=L(t) \frac{c^{1-\alpha}(t)}{1-\alpha}$,

$c(t)=1000 \frac{C(t)}{L(t)}$,

$Q(t)=(1-\Lambda(t)) \Omega(t) Y(t)=C(t)+I(t)$,

$I(t)=s(t) Q(t)$

$\Lambda(t)=\theta_{1}(t) \mu^{\theta_{2}}(t)$,

$\Omega(t)=\frac{1}{1+D(t)}$,

$D(t)=a T_{\mathrm{AT}}^{2}(t)$,

$Y(t)=A(t) K^{\gamma}(t)\left[\frac{L(t)}{1000}\right]^{1-\gamma}$,

$E_{\text {Ind }}(t)=\sigma(t)(1-\mu(t)) Y(t)$,

$E(t)=E_{\text {Ind }}(t)+E_{\text {Land }}(t)$,

$F(t)=\eta \log _{2} \frac{M_{\mathrm{AT}}(t)}{M_{\mathrm{AT}}(1750)}+F_{\mathrm{EX}}(t)$,

$\sigma(t+1)=\sigma(t) e^{-5 g_{\sigma}\left(1-d_{\sigma}\right)^{5(t-1)}}, \sigma(1)=\sigma^{1}$,

$E_{\text {Land }}(t)=E_{\text {Land }}^{1}\left(1-d_{E}\right)^{t-1}$,

$F_{\mathrm{EX}}(t)=\left\{\begin{array}{lr}F_{\mathrm{EX}}^{1}+\frac{\left(F_{\mathrm{EX}}^{2}-F_{\mathrm{EX}}^{1}\right)(t-1)}{t_{F}-1}, t=1, \ldots, t_{F}-1, \\ F_{\mathrm{EX}}^{2}, & t=t_{F}, \ldots ;\end{array}\right.$

$\theta_{1}(t)=\frac{\theta_{1}^{1}}{1000 \theta_{2}}\left(1-d_{\theta}\right)^{t-1} \sigma(t)$,

$L(t+1)=L(t)\left[\frac{L_{\max }}{L(t)}\right]^{g_{L}}, L(1)=L^{1}$,

$A(t+1)=\frac{A(t)}{1-g_{A} \mathrm{e}^{-d_{A} \cdot 5(t-1)}}, A(1)=A^{1}$.

All the parameters are listed in the Table 1.

\begin{tabular}{|l|l|l|}
\hline Parameter & Value & Description (unit) \\
\hline Initial values (2010) \\
\hline$K^{1}$ & 135 & Initial capital value (trillions 2005 USD) \\
\hline
\end{tabular}




\begin{tabular}{|c|c|c|}
\hline$M_{\mathrm{AT}}^{1}$ & 830.4 & Initial concentration in atmosphere (GtC) \\
\hline$M_{\mathrm{UP}}^{1}$ & 1527 & Initial concentration in upper strata $(\mathrm{GtC})$ \\
\hline$M_{\mathrm{LO}}^{1}$ & 10,010 & Initial concentration in lower strata (GtC) \\
\hline$T_{\mathrm{AT}}^{1}$ & 0.8 & Initial atmospheric temperature change from $1900\left({ }^{\circ} \mathrm{C}\right)$ \\
\hline$T_{\mathrm{LO}}^{1}$ & 0.0068 & Initial lower stratum temperature change from $1900\left({ }^{\circ} \mathrm{C}\right)$ \\
\hline$A^{1}$ & 3.8 & $\begin{array}{l}\text { Initial level of total factor productivity ((thousands } 2005 \\
\text { USD/ millions of people })^{1-\gamma} \text { ) }\end{array}$ \\
\hline$L^{1}$ & 6838 & Initial world population (millions of people) \\
\hline$\sigma^{1}$ & 0.5491 & $\begin{array}{l}\text { Initial carbon intensity (tons } \mathrm{CO}_{2} \text { per year / thousands } 2005 \\
\text { USD) }\end{array}$ \\
\hline$\mu^{1}$ & 0.035 & Initial emissions control rate \\
\hline$E_{\text {Land }}^{1}$ & 3.3 & Initial carbon emissions from land $\left(\mathrm{GtCO}_{2}\right.$ per year) \\
\hline$F_{\mathrm{EX}}^{1}$ & 0.25 & Initial forcings of non- $\mathrm{CO}_{2} \mathrm{GHG}\left(\mathrm{W} / \mathrm{m}^{2}\right)$ \\
\hline$\theta_{1}^{1}$ & 344 & $\begin{array}{l}\text { Initial cost of backstop technology at } 100 \% \text { removal (2005 } \\
\text { USD per ton of } \mathrm{CO}_{2} \text { ) }\end{array}$ \\
\hline \multicolumn{3}{|c|}{ Preferences } \\
\hline$\rho$ & 0.015 & Rate of social time preference (1 / year) \\
\hline$\alpha$ & 1.45 & Elasticity of the marginal utility w.r.t. consumption \\
\hline \multicolumn{3}{|c|}{ Population and technology } \\
\hline$\delta$ & 0.1 & Depreciation rate on capital (1 / year) \\
\hline$\gamma$ & 0.3 & Capital elasticity in production function \\
\hline$g_{L}$ & 0.134 & Exponent defining the population growth \\
\hline$L_{\max }$ & 10500 & Asymptotic population (millions of people) \\
\hline$g_{A}$ & 0.079 & $\begin{array}{l}\text { Proportionality coefficient defining the total factor } \\
\text { productivity (TFP) growth }\end{array}$ \\
\hline$d_{A}$ & 0.006 & Exponent defining the TFP growth deceleration (1 / year) \\
\hline \multicolumn{3}{|c|}{ Carbon cycle } \\
\hline$\xi_{1}$ & $1 / 3.666$ & $\begin{array}{l}\text { Conversion factor of emissions into concentrations (GtC } \\
\mathrm{GtCO}_{2} \text { ) }\end{array}$ \\
\hline$\phi_{21}$ & 0.03833 & $\begin{array}{l}\text { Rate of exchange of } \mathrm{CO}_{2} \text { from upper ocean to atmosphere } \\
\text { per } 5 \text { years (fraction of } M_{\mathrm{UP}}(t) \text { ) }\end{array}$ \\
\hline$\phi_{12}$ & 0.088 & $\begin{array}{l}\text { Rate of exchange of } \mathrm{CO}_{2} \text { from atmosphere to upper ocean } \\
\text { per } 5 \text { years (fraction of } M_{\mathrm{AT}}(t) \text { ) }\end{array}$ \\
\hline$\phi_{32}$ & 0.0003375 & $\begin{array}{l}\text { Rate of exchange of } \mathrm{CO}_{2} \text { from lower ocean to upper ocean } \\
\text { per } 5 \text { years (fraction of } M_{\mathrm{LO}}(t) \text { ) }\end{array}$ \\
\hline
\end{tabular}




\begin{tabular}{|c|c|c|}
\hline$\phi_{23}$ & 0.0025 & $\begin{array}{l}\text { Rate of exchange of } \mathrm{CO}_{2} \text { from upper ocean to lower ocean } \\
\text { per } 5 \text { years (fraction of } M_{\mathrm{UP}}(t) \text { ) }\end{array}$ \\
\hline$M_{\mathrm{AT}}(1750)$ & 588 & Pre-industrial level of carbon in atmosphere (GtC) \\
\hline \multicolumn{3}{|c|}{ Temperature and radiative forcings } \\
\hline$\eta$ & 3.8 & Forcings of equilibrium $\mathrm{CO}_{2}$ doubling $\left(\mathrm{W} / \mathrm{m}^{2}\right)$ \\
\hline$\zeta_{1}$ & 0.098 & Diffusion parameter for atmospheric layer $\left(\mathrm{m}^{2} / \mathrm{W}\right)$ \\
\hline$\zeta_{2}$ & 2.9 & $\begin{array}{l}\text { Equilibrium climate sensitivity }\left({ }^{\circ} \mathrm{C} \text { of equilibrium } \mathrm{CO}_{2}\right. \\
\text { doubling) }\end{array}$ \\
\hline$\zeta_{3}$ & 0.088 & $\begin{array}{l}\text { Transfer coefficient from lower ocean to atmospheric layer } \\
\left(\mathrm{W} / \mathrm{m}^{2} /{ }^{\circ} \mathrm{C}\right)\end{array}$ \\
\hline$\zeta_{4}$ & 0.025 & Diffusion parameter for lower ocean layer \\
\hline$F_{\text {EX }}^{2}$ & 0.7 & 2100 forcings of non-CO ${ }_{2}$ GHG $\left(\mathrm{W} / \mathrm{m}^{2}\right.$ ) \\
\hline$t_{F}$ & 19 & $\begin{array}{l}\text { The time ( } 2100 \text { year) for which the estimation of forcings } \\
\text { of non-CO }{ }_{2} \text { GHG is used }\end{array}$ \\
\hline \multicolumn{3}{|l|}{ Emissions } \\
\hline$d_{\sigma}$ & 0.001 & Decline rate of decarbonization per year \\
\hline$g_{\sigma}$ & 0.01 & Initial decline of carbon intensity level per year \\
\hline$d_{E}$ & 0.2 & Decline rate of land emissions per 5 years \\
\hline \multicolumn{3}{|c|}{ Other parameters } \\
\hline$a$ & 0.00267 & $\begin{array}{l}\text { Fraction of damaged GDP w.r.t. } 1{ }^{\circ} \mathrm{C} \text { atmospheric } \\
\text { temperature change from } 1900\left(1 /\left({ }^{\circ} \mathrm{C}\right)^{2}\right)\end{array}$ \\
\hline$\theta_{2}$ & 2.8 & Exponent of the control cost function \\
\hline$T$ & 100 & Time horizon $^{17}$ (periods) \\
\hline$d_{\theta}$ & 0.025 & Initial decline of backstop cost per 5 years \\
\hline$t_{\mu}$ & 30 & $\begin{array}{l}\text { The time (2155 year) from which negative emissions are } \\
\text { possible }\end{array}$ \\
\hline
\end{tabular}

Table 1. Parameters of the DICE-2013R model.

\section{$B$ Two alternative ways of representing the climate change damage to GDP in the DICE model}

In the GAMS code of the original DICE-2013R model, GDP net of damages and abatement is written as follows:

\footnotetext{
${ }^{17}$ In the original DICE code $T=60$ and the optimal fraction of savings, $s(t)$, is fixed to the equilibrium value for last ten time periods.
} 
$Q(t)=[1-\Lambda(t)-D(t)] Y(t)$.

Here $\Lambda(t)$ and $D(t)$ are defined by formulas (A.1) and (A.2) respectively. This formula appears also in (Kellett et al., 2016) where the authors tried to replicate DICE-2013R model in the their own code developed in MATLAB.

On the other hand, in all previous versions of the DICE model (see, e.g., (W. Nordhaus and Sztorc 2013; Kellett, Faulwasser, and Weller 2016)) as well as in most of the papers devoted to the DICE model, the following formula is used for $Q(t)$ (sometimes with different values of parameters in $\Lambda(t)$ and $D(t)$ )

$Q(t)=[1-\Lambda(t)] \frac{1}{1+D(t)} Y(t)$.

Formulas (B.1), (B.2) are equivalent within the accuracy of the first-order Taylor series approximation in the neighborhood of zero damages and zero abatement effort:

$1-\Lambda(t)-D(t) \approx[1-\Lambda(t)][1-D(t)] \approx[1-\Lambda(t)] \frac{1}{1+D(t)}$.

We think that formula (B.2) has a slightly clearer logic because it takes advantage of the subsequent order of climate change damages and abatement costs, which can only be subtracted from the remaining GDP after the damages. Thus, in our GAMS code we use Eq. (B.2) instead of (B.1), which is also consistent with a big chunk of literature devoted to IAMs.

\section{Sensitivity analysis w.r.t. damage function}

The form and parameters of the climate damage function are one of the biggest uncertainties in the literature on IAMs. In this section we examine how the results obtained in this paper are dependent of the choice of the damage function. To shed some light on this question, we carried out simulations with three alternative damage functions:

- Original damage function from DICE-2013R: $\Omega(t)=\frac{1}{1+0.00267 T_{A T}^{2}(t)}$

- Damage function from DICE-2016R ${ }^{18}: \Omega(t)=\frac{1}{1+0.00236 T_{A T}^{2}(t)}$

- Weitzman damage function (Wouter Botzen and van den Bergh 2012): $\Omega(t)=$ $\frac{1}{1+\left[\frac{T_{A T}(t)}{20.46}\right]^{2}+\left[\frac{T_{A T}(t)}{6.081}\right]^{6.754}}$

${ }^{18}$ http://www.econ.yale.edu/ nordhaus/homepage/DICE2016R-091916ap.gms [Accessed 9.10.2017] 


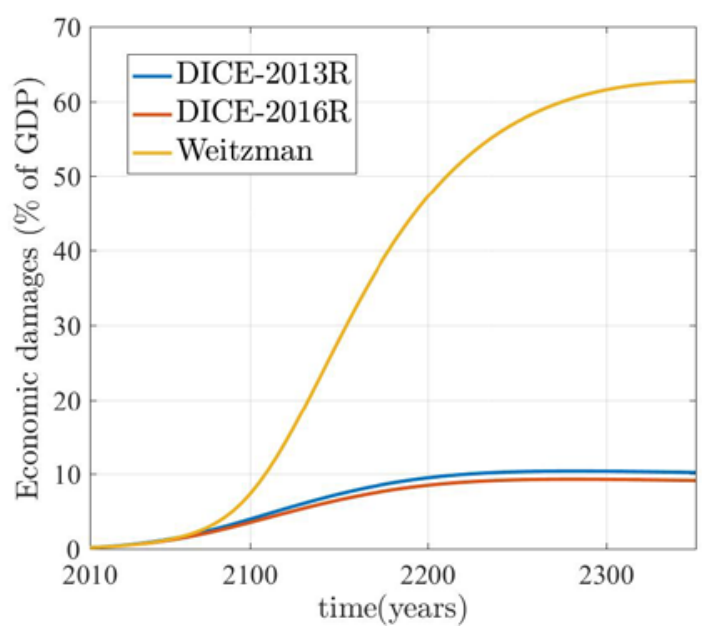

Figure C1. Damages as shares of GDP in per cents (three alternative damage functions, NM scenario)

Figure C1 shows economic damages in per cents of GDP in NM scenario for these three damage functions. In the initial period of time (roughly before the year 2080) the differences are not as significant. Afterwards Weitzman damage function delivers radically higher damages than the DICE damage functions. DICE-2016R damage function delivers damages higher than DICE-2013R one by about $1 \%$.

While the difference between Weitzman damage function and Nordhaus damage function was thoroughly analyzed in (Wouter Botzen and van den Bergh 2012), here we show that actually the results of our paper qualitatively are rather robust with respect to the choice of the damage function (between these three). Figures C2 and C3 show the abatement part of the GDP net of damages and the tax part of the GDP net of damages for the three considered damage functions. We observe that structure of policies does not depend on the damage function: The three phases - bonds issuance, bonds repayment and taxes - emerge as a result of the optimal choice of the central planner independently from the particular damage function. Expectedly, the higher climate damages lead to higher optimal abatement and taxation. 


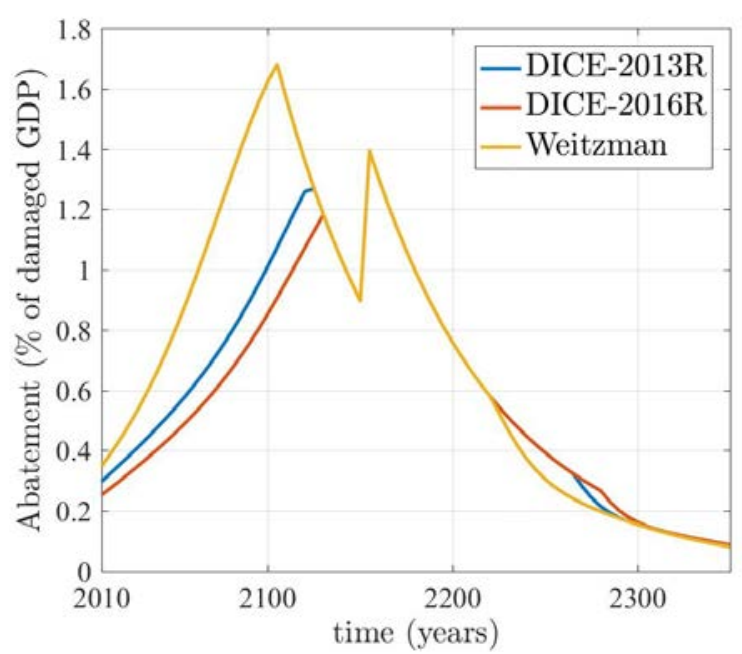

Figure C2. Abatement part of GDP net of damages (three damage functions, OMB scenario)

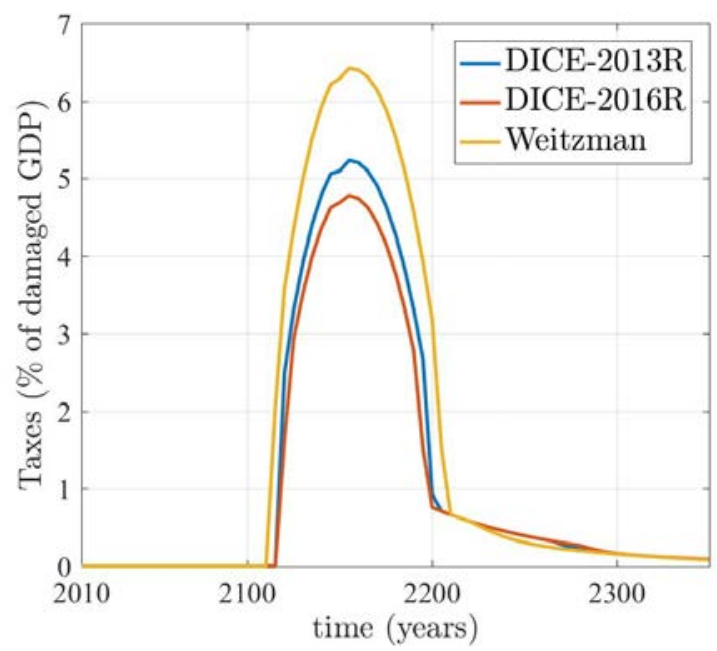

Figure C3. Tax part of GDP net of damages in per cents (three damage functions, OMB scenario) 